\title{
ANALISIS KeSALAHAN SISWA BERDASARKAN TAHAPAN NEWMAN DAN SCAFFOLDING PADA MATERI ARITMATIKA SOSIAL
}

\section{ANALYSIS OF STUDENT ERROR BASED ON STAGE OF NEWMAN AND SCAFFOLDING ON SOCIAL ARITHMATIC MATERIAL}

\author{
Puji Lestari Susilowati ${ }^{1}$ dan Novisita Ratu $^{\mathbf{2}}$ \\ 1Program Studi Pendidikan Matematika, Universitas Kristen Satya Wacana \\ Jl. Diponegoro No. 52-60 Sidorejo, Salatiga, Jawa Tengah, Indonesia \\ plsusilowati@gmail.com \\ 2 Program Studi Pendidikan Matematika, Universitas Kristen Satya Wacana \\ Jl. Diponegoro No. 52-60 Sidorejo, Salatiga, Jawa Tengah, Indonesia \\ novisita.ratu@staff.uksw.edu
}

\begin{abstract}
Abstrak
Tujuan penelitian ini adalah untuk mengidentifikasi kesalahan siswa berdasarkan Tahapan Newman dan scaffolding pada materi aritmatika sosial. Penelitian ini merupakan penelitian tindakan. Subjek penelitian ini adalah siswa SMP Pangudi Luhur Salatiga kelas VII. Teknik pengumpulan data yang digunakan adalah tes dan wawancara klinis. Instrumen penelitian dalam penelitian ini adalah peneliti sendiri dan dibantu oleh instrumen pendukung berupa soal tes dan pedoman wawancara. Teknik analisis data yang digunakan mencakup transkrip hasil wawancara, reduksi data, analisis, dan triangulasi. Hasil penelitian menunjukan bahwa kesalahan yang dilakukan siswa pada tipe kesalahan I (reading error) sebesar 8,33\%, tipe kesalahan II (reading comprehension difficulty) sebesar 13,64\%, tipe kesalahan III (transform error) sebesar 14,39\%, tipe kesalahan IV (weakness in process skill) sebesar 31,82\%, tipe kesalahan $\vee$ (encoding error) sebesar $31,82 \%$. Scaffolding yang digunakan untuk mengatasi semua kesalahan hanya sampai pada scaffolding level 2. Scaffolding yang diberikan pada kesalahan tipe I dan II adalah explaining, scaffolding yang diberikan pada kesalahan tipe III adalah explaining dan reviewing. Scaffolding yang diberikan pada kesalahan tipe IV adalah explaining, reviewing, dan restructuring, sedangkan scaffolding yang diberikan pada kesalahan tipe $\mathrm{V}$ adalah explaining.

Kata Kunci: analisis kesalahan, aritmatika sosial, scaffolding.
\end{abstract}

\begin{abstract}
The purpose of this study was to identify students' errors based on Newman Stages and scaffolding in social arithmetic material. This research is an action research. The subject of this research is Pangudi Luhur Salatiga class VII students. Data collection techniques used are tests and clinical interviews. The research instrument in this research is the researcher himself and assisted by supporting instrument in the form of test question and interview guide. Data analysis techniques used include transcript of interview result, data reduction, analysis, and triangulation. The result of the research showed that the mistake of the students on the type error I (reading error) of $8.33 \%$, the type of error II (reading comprehension difficulty) of 13.64\%, type error III (transform error) of $14.39 \%$, type error IV (weakness in process skill) of $31.82 \%$, error type $V$ (encoding error) of $31.82 \%$. Scaffolding used in this study only until scaffolding at level II. Scaffolding given to type I and II errors is explaining, the scaffolding given to type III errors is explaining and reviewing. Scaffolding given to type IV errors is explaining, reviewing, and restructuring, while the scaffolding given to type $V$ errors is explaining.

Keyword: error analysis, social arithmetic, scaffolding.
\end{abstract}

Jurnal "Mosharafa", Volume 7, Nomor 1, Januari 2018 


\section{Pendahuluan}

Penguasaan kemampuan penyelesaian soal matematika dalam bentuk soal cerita sangatlah penting bagi siswa. Aritmatika sosial adalah salah satu materi yang memuat masalah nyata dalam bentuk soal cerita. Hal ini dibuktikan oleh penelitian Setyono (2013) pada siswa SMP Muhamadiyah 5 Surakarta dimana tingkat kesalahan siswa dalam menyelesaikan soal matematika dalam bentuk cerita pada pokok bahasan aritmatika sosial seluruh tahap masih tergolong cukup tinggi, yaitu sebesar 54,84\%. Hal ini juga terjadi pada siswa kelas VII SMP Pangudi Luhur Salatiga. Berdasarkan wawancara dan tes, diperoleh kesimpulan bahwa terdapat beberapa kesalahan siswa dalam mengerjakan soal cerita aritmatika sosial. Kesalahan yang dibuat oleh siswa dapat dilihat pada gambar 1 .

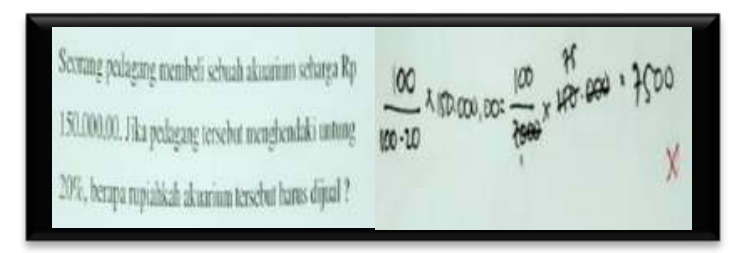

Gambar 1. Jawaban siswa dalam menentukan Harga Penjualan.

Pada gambar 1, tampaklah bahwa siswa melakukan kesalahan dalam konsep, yaitu siswa salah menggunakan rumus, dan kesalahan dalam menghitung. Kesalahan ini dilakukan oleh beberapa siswa dan masih banyak kesalahan yang dibuat siswa dalam menyelesaikan soal cerita aritmatika sosial.
Salah satu cara untuk menganalisis kesalahan yang dilakukan siswa dalam menyelesaikan soal matematika adalah teori Newman. Analisis kesalahan ini ditemukan oleh seorang guru matematika di Australia yang pertama kali memperkenalkan metode analisis kesalahan dan diberi nama analisis kesalahan Newman. Menurut Newman (Clement, 1980), terdapat 5 tipe kesalahan yang dilakukan siswa dalam mengerjakan soal matematika, yaitu (1) reading error (kesalahan membaca) terjadi karena siswa salah membaca soal. Sehingga membuat jawaban siswa tidak sesuai dengan maksud soal; (2) comprehension error (kesalahan memahami) terjadi karena siswa kurang memahami konsep, siswa tidak mengetahui apa yang ditanyakan pada soal dan salah dalam menangkap informasi yang ada pada soal; (3) transform error (kesalahan dalam transformasi) merupakan kesalahan yang terjadi karena siswa belum dapat mengubah soal kedalam bentuk matematika dengan benar; (4) weakness in process skill (kesalahan dalam keterampilan proses) terjadi karena siswa belum terampil dalam melakukan perhitungan; (5) enconding error (kesalahan pada notasi) merupakan kesalahan dalam proses penyelesaian.

Penting bagi seorang guru mengetahui kesalahan yang dilakukan oleh siswa. Kesalahan tersebut perlu dianalisis untuk mengetahui kesalahan-kesalahan yang dilakukan siswa, sehingga diharapkan siswa tidak melakukan kesalahan yang sama (Putri, 2016). Menurut Suhertin 
dalam Grahita (2014) penyebab kesalahankesalahan yang dilakukan siswa dalam mengerjakan soal cerita matematika dikarenakan siswa kurang menguasai bahasa, contohnya siswa tidak paham dengan pertanyaan, tidak memahami arti kata, tidak memahami konsep, dan kurang memahami teknik berhitung.

Pemberian bantuan kepada siswa yang mengalami kesulitan dalam menyelesaikan masalah berdasarkan konsep Vygotsky tentang assisted-learning, merupakan teknik pemberian bantuan pada tahap awal yang diberikan secara terstruktur, bantuan tersebut disebut dengan scaffolding. Vygotsky menyatakan siswa akan dapat menyelesaikan masalah jika mendapat bantuan dari orang yang lebih mampu. Felayani (2013) menyatakan bahwa scaffolding adalah suatu proses yang digunakan orang dewasa untuk menuntun anak-anak melalui Zone of proximal development-nya. Scaffolding berasal dari kata scaffold yang berarti tangga untuk pijakan tukang batu ketika membangun tembok. Sehingga scaffolding dapat diartikan sebagai bantuan yang disediakan teman yang lebih kompeten atau orang dewasa.

Menurut Anghileri (2006) terdapat tiga tingkat scaffolding sebagai serangkaian strategi yang efektif, tingkat pertama adalah enviromental provisions yaitu penataan lingkungan belajar, tingkat kedua adalah explaining, reviewing, and restructuring yang artinya interaksi guru untuk mendukung siswa belajar, tingkat ketiga adalah developing conceptual thingking yaitu interaksi guru untuk pengembangan pemikiran konseptual. Ketiga tingkatan tersebut dapat dilihat pada gambar dibawah ini.

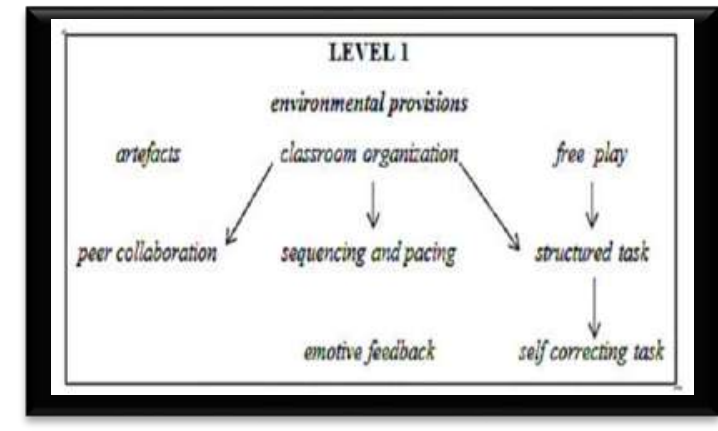

Gambar 2. Scaffolding Level 1.

Tingkat ini siswa diberikan dukungan untuk dapat belajar mandiri. Guru hanya menyediakan lingkungan belajar misalnya dengan menentukan kelompok belajar. Selain itu, guru dapat memberikan tugas terstruktur.

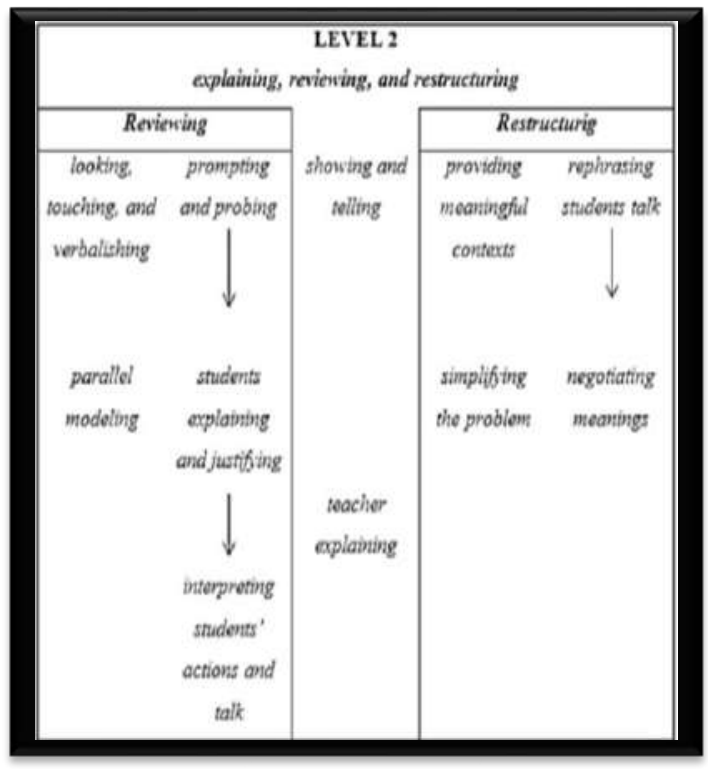

Gambar 3. Scaffolding Level 2.

Pada tahap ini, terdapat tiga insfraksi, 1) menjelaskan (explaining) yaitu cara 
menyampaikan konsep yang dipelajari; 2) meninjau (reviewing) yaitu mengidentifikasi aspek-aspek yang penting berkaitan dengan konsep matematika atau masalah yang akan dipecahkan; dan 3) restrukturasi (restructuring) yaitu merestrukturasi jawaban siswa yang telah dibuat.

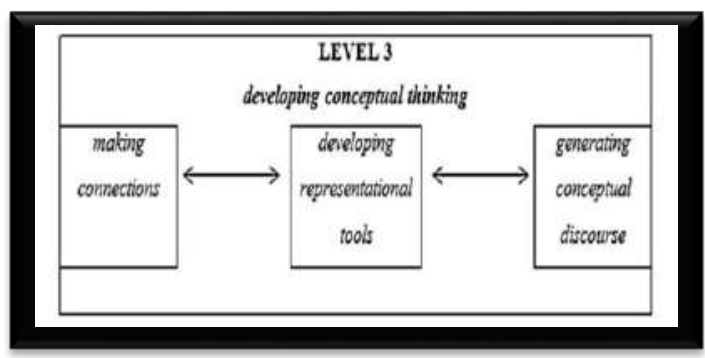

Gambar 4. Scaffolding Level 3.

Tingkat ketiga adalah developing conceptual thingking yaitu interaksi guru untuk mengembangkan pemikiran konseptual (Anghileri dalam Istiqomah dan Setyaningsih, 2013).

Berdasarkan uraian diatas rumusan masalah pada penelitian ini adalah apakah pemberian scaffolding dapat mengatasi kesalahan siswa berdasarkan tahapan newman pada materi aritmatika sosial?. Sehingga penelitian ini dilakukan dengan tujuan untuk mengidentifikasi bahwa pemberian scaffolding dapat mengatasi kesalahan siswa berdasarkan tahapan newman pada materi aritmatika sosial.

\section{Metode}

Penelitian ini termasuk dalam penelitian tindakan dengan pendekatan kualitatif. Subjek Penelitian ini adalah siswa SMP Pangudi Luhur Salatiga pada kelas VII yang ditentukan dengan menggunakan purposive sampling, yaitu pengambilan sampel dengan pertimbangan tertentu (Sugiyono, 2013). Kemudian dipilih 3 siswa yang melakukan kesalahan terbanyak pada ketiga soal dan semua tipe kesalahan. Teknik pengumpulan data yang digunakan adalah tes dan wawancara klinis. Instrumen penelitian dalam penelitian ini adalah peneliti sendiri dan dibantu oleh instrumen pendukung berupa soal tes dan pedoman wawancara. Teknik validitas instrumen yang digunakan adalah uji validitas konstruksi melalui pendapat para ahli (Sugiyono, 2010). Teknik analisis data yang digunakan mencakup transkrip hasil wawancara, reduksi data, analisis, dan triangulasi.

\section{Hasil dan Pembahasan}

Instrumen penelitian ini menggunakan soal cerita aritmatika sosial. Soal tes yang diberikan terdiri dari 3 soal uraian yang berhubungan dengan masalah dalam kehidupan sehari-hari. Hasil pekerjaan siswa dapat dilihat apada tabel 1 .

Tabel 1.

Hasil Pekerjaan Siswa

\begin{tabular}{|ccccc|}
\hline \multirow{2}{*}{ No Soal } & \multicolumn{4}{c}{ Keterangan } \\
\cline { 2 - 5 } \multicolumn{1}{c}{$\sum$ B } & $\sum$ S & $\sum$ TM & Total \\
\hline 1 & 17 & 7 & 0 & 24 \\
\hline 2 & 1 & 23 & 0 & 24 \\
\hline 3 & 4 & 8 & 12 & 24 \\
\hline Jumlah & 22 & 38 & 12 & 72 \\
\hline Persentase & $30,56 \%$ & $52,77 \%$ & $16,67 \%$ & $100 \%$ \\
\hline
\end{tabular}

Keterangan:

$\Sigma \mathrm{B} \quad$ : Jumlah siswa yang menjawab benar

¿S : Jumlah siswa yang menjawab salah

¿TM : Jumlah siswa yang tidak menjawab 
Berdasarkan tabel di atas, dapat diketahui bahwa persentase jawaban salah yaitu 52,77\% dengan jumlah seluruh kesalahan adalah 38 siswa. Persentase jawaban siswa yang benar sebesar 30,56\% dengan jumlah jawaban benar sebanyak 22. Soal nomor satu merupakan soal dengan jawaban benar terbanyak, yaitu sebanyak 17 siswa menjawab dengan benar. Persentase paling sedikit adalah persentase siswa yang tidak menjawab soal yaitu sebesar 16,67\%. Sebanyak 12 siswa tidak menjawab soal nomor tiga, sedangkan pada soal nomor 1 , dan 2, semua subjek menjawabnya meskipun terdapat beberapa jawaban yang salah. Kesalahan yang dilakukan oleh siswa dapat dilihat pada tabel 2 .

Tabel 2.

Tiap Tipe Kesalahan

\begin{tabular}{|c|c|c|c|c|c|}
\hline \multirow{2}{*}{$\begin{array}{l}\text { Kesalahan } \\
\text { Tipe }\end{array}$} & \multicolumn{3}{|c|}{ Nomor Soal } & \multirow[t]{2}{*}{ Total } & \multirow[t]{2}{*}{ Persentase } \\
\hline & 1 & 2 & 3 & & \\
\hline 1 & 2 & 7 & 2 & 11 & $08,33 \%$ \\
\hline 2 & 5 & 7 & 6 & 18 & $13,64 \%$ \\
\hline 3 & 6 & 7 & 6 & 19 & $14,39 \%$ \\
\hline 4 & 7 & 23 & 12 & 42 & $31,82 \%$ \\
\hline 5 & 7 & 23 & 12 & 42 & $31,82 \%$ \\
\hline
\end{tabular}

Keterangan :

Kesalahan Tipe 1 : Reading Error

Kesalahan Tipe 2 : Reading Comprehension

Difficulty

Kesalahan Tipe 3 : Transform Error

Kesalahan Tipe 4 : Weakness in Process Skill

Kesalahan Tipe 5 : Encoding Error

\section{A. Tipe 1, Reading Error}

Kesalahan pada butir soal nomor 1 dilakukan oleh satu subjek yaitu subjek MI. Berdasarkan tanya jawab dengan subjek MI, melakukan kesalahan dengan tidak menghitung sisa jumlah barang yang dijual pada soal.

\section{Sebelum Scaffolding}

Kesalahan yang dilakukan subjek pada butir soal nomor 1 karena subjek salah membaca informasi utama yang terdapat dalam soal. Berikut hasil pekerjaan subjek MI dapat dilihat pada gambar 5 .

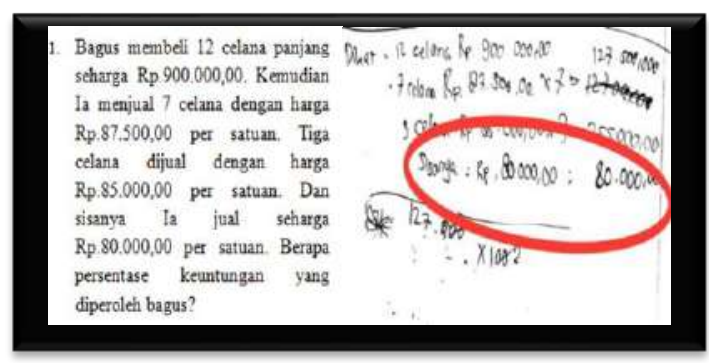

Gambar 5. Hasil Pekerjaan Subjek MI Pada Butir Soal Nomor 1.

\section{Bentuk Scaffolding}

Berdasarkan wawancara ternyata subjek MI salah dalam membaca informasi utama yang terdapat dalam soal. Peneliti memberikan pertanyaan arahan agar subjek mengetahui letak kesalahanya dan meminta subjek $\mathrm{MI}$ menemukan sendiri untuk memecahkan masalah kemudian diminta melihat kembali hasil pekerjaanya. scaffolding yang diberikan tersebut apabila dikategorikan dengan scaffolding Anghileri (2006), pemberian scaffolding ini berada pada level 2 explaining (menjelaskan).

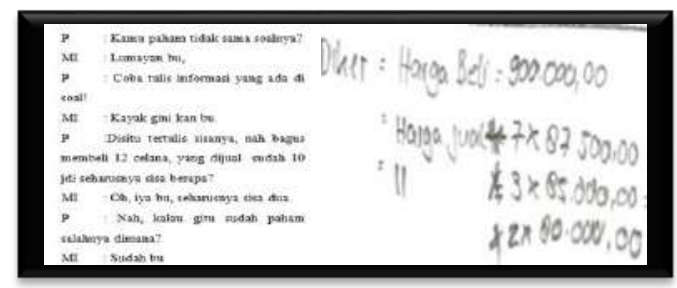

Gambar 6. Scafolding Kesalahan Tipe 1 Pada Butir Soal Nomor 1. 


\section{Setelah Scaffolding}

Setelah subjek dapat memahami soal dengan benar peneliti memberikan soal tipe sama untuk dikerjakan lagi tetapi tanpa bantuan peneliti. Soal Tambahan dan hasil jawaban subjek dapat dilihat pada gambar 7 .

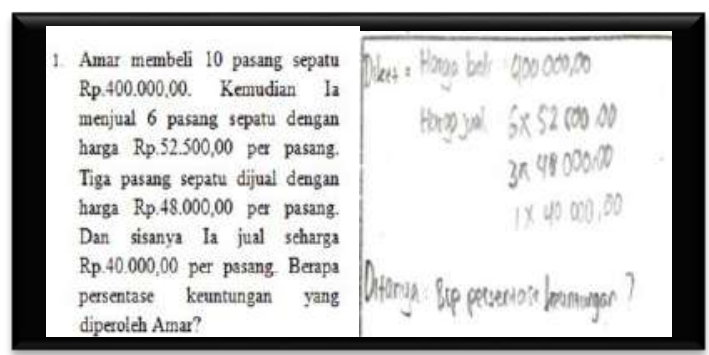

Gambar 7. Hasil Pekerjaan Subjek MI Pada Soal Tambahan Butir Soal Nomor 1.

Subjek MI mengerjakan soal tambahan pada butir soal nomor 1 dengan benar, maka proses scaffolding bagi subjek $\mathrm{MI}$ dianggap selesai.

\section{B. Tipe 2, Reading Comprehension Difficulty}

Kesalahan pada butir soal nomor 2 dilakukan oleh subjek MI, DA, dan YR. Wawancara dilakukan oleh peneliti dengan subjek MI, DA, dan YR, diketahui bahwa subjek YR tidak terlalu memahami soal, sehingga tidak dapat menyelesaikan soal. Berikut pembahasannya.

\section{Sebelum Scaffolding}

Berdasarkan wawancara dengan subjek YR, dapat diketahui bahwa subjek YR kurang memahami soal dan hanya mencoba-coba saja.
2. Toko April memberikan diskon untuk baju lebaran sebesar $30 \%$, celana $20 \%$, kemudian untuk sepatu dan tas $30 \%+10 \%$. Prilly membeli 2 baju seharga Rp. $840.000,00$ dan sebuah tas seharga Rp.400.000,00. Sedangkan Ali membeli sebuah celana seharga Rp.360.000,00 dan sepasang sepatu seharga Rp. $500.000,00$. Berapa uang yang harus dibayar oleh Ali dan Prilly?

$30 \mathrm{~b} \rightarrow$ bajk

$20 ! \rightarrow$ ciono

$30 q+10 q \rightarrow \operatorname{tas}$

$2(309 \times 890000)+(30 \%+159 \times 40000)$

$2(20 q \times 360000)+(39+10 q+500)$

jearb $(2 \times 126000)+(120000+40000$

$=252000+1600000$

$=41.2000$

jack $+72000+(130.000+100.000)$

Gambar 8. Hasil Pekerjaan Subjek YR Pada Butir Soal Nomor 2.

\section{Bentuk Scaffolding}

Peneliti memberikan pertanyaan arahan agar subjek mengetahui informasi pada soal dan meminta subjek YR untuk memecahkan masalah kemudian diminta melihat kembali hasil pekerjaanya. Scaffolding yang diberikan tersebut apabila dikategorikan dengan scaffolding Anghileri (2006), pemberian scaffolding ini berada pada level 2 explaining (menjelaskan). 


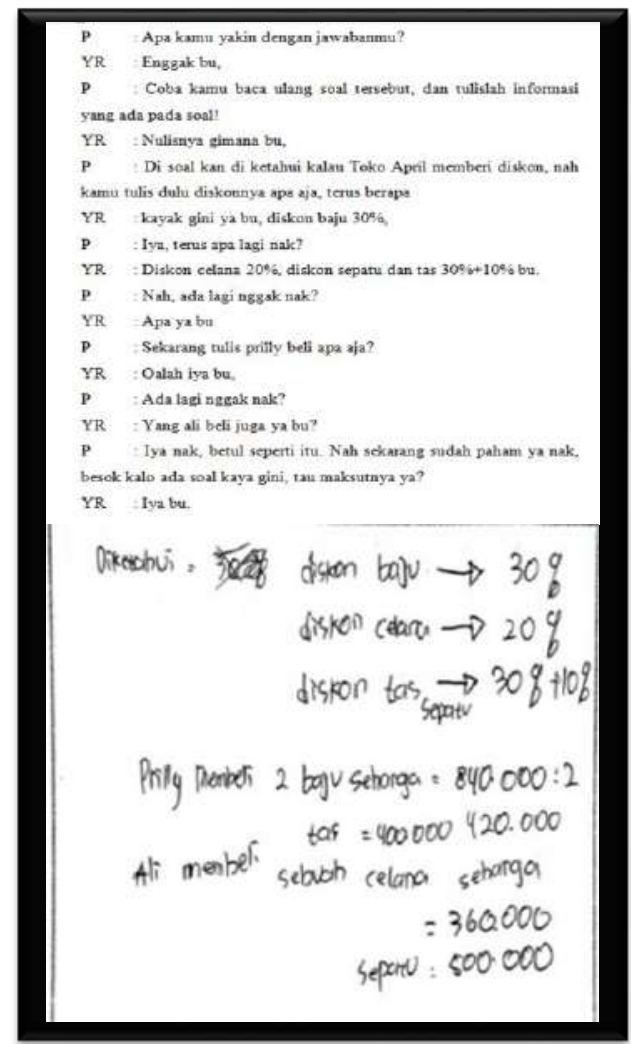

Gambar 9. Scaffolding Kesalahan Tipe 2 Pada Butir Soal Nomor 2.

\section{Setelah Scaffolding}

Setelah proses pemberian scaffolding dan subjek YR sudah paham, maka subjek harus mengerjakan kembali soal tambahan yang terdapat pada gambar 10. Hasil pekerjaan soal tambahan oleh subjek dapat dilihat pada gambar berikut.

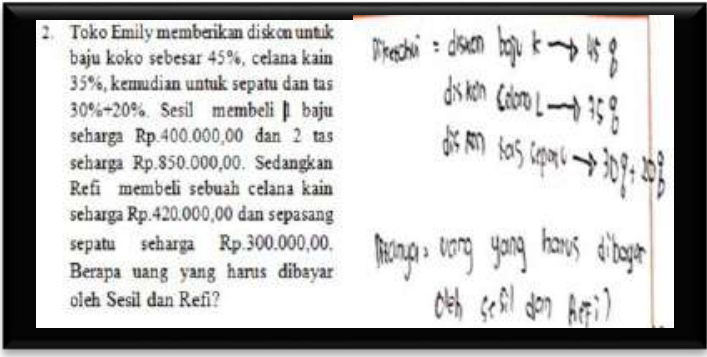

Gambar 10. Hasil Pekerjaan Subjek YR Pada Soal Tambahan Butir Soal Nomor 2.
Gambar 10 adalah penyelesaian soal tambahan yang diberikan peneliti kepada YR. Terlihat bahwa hasil yang dikerjakan YR adalah benar, maka proses scaffolding dinyatakan selesai.

\section{Tipe 3, Transform Error}

Kesalahan pada butir soal nomor 2 dilakukan oleh tiga subjek yaitu subjek DA, MI dan YR dengan kesalahan yaitu subjek gagal untuk mengubah soal kedalam kalimat matematika. Berikut contoh hasil pekerjaan subjek YR.

\section{Sebelum Scaffolding}

Berdasarkan wawancara yang dilakukan oleh peneliti dengan subjek YR, diketahui bahwa subjek YR tidak terlalu memahami soal, dan juga sulit untuk mengubah soal kedalam kalimat matematika.

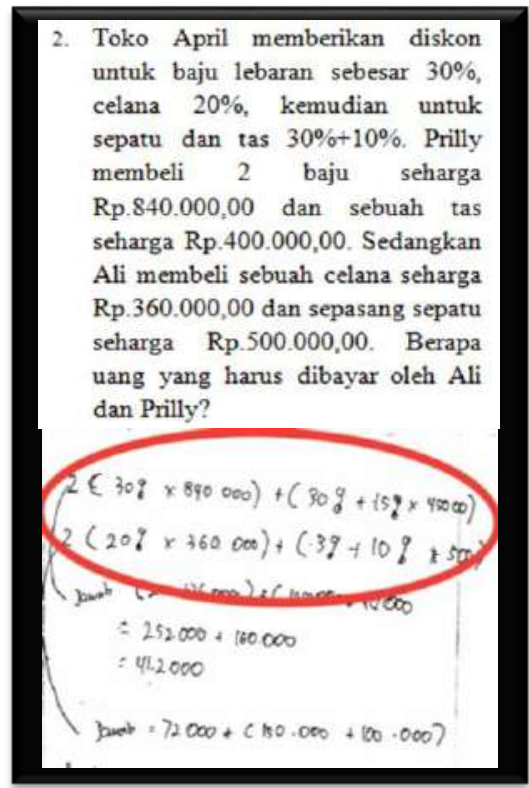

Gambar 11. Hasil Pekerjaan Subjek YR Pada Butir Soal Nomor 2.

\section{Bentuk Scaffolding}

Peneliti memberikan pertanyaan arahan agar subjek mengetahui informasi 
pada soal dan meminta subjek YR untuk memecahkan masalah kemudian diminta melihat kembali hasil pekerjaanya. Scaffolding yang diberikan tersebut apabila dikategorikan dengan scaffolding Anghileri (2006), pemberian scaffolding ini berada pada level 2 explaining (menjelaskan), dan reviewing (meninjau).

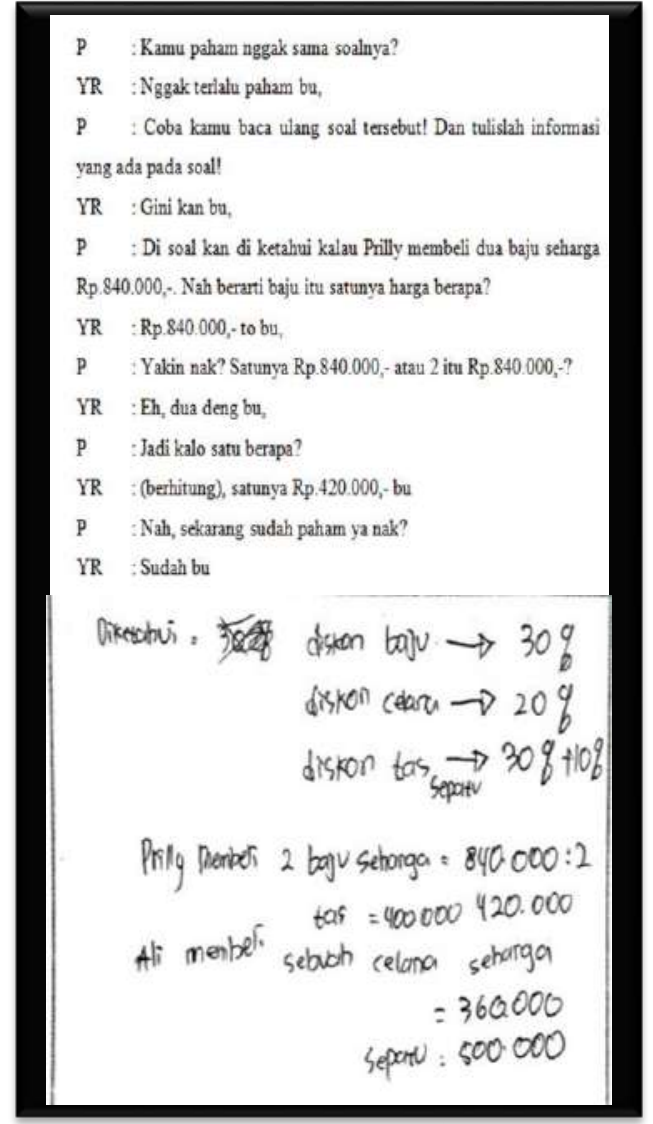

Gambar 12. Scaffolding Kesalahan Tipe 3 Pada Butir Soal Nomer 2.

\section{Setelah Scaffolding}

Tahapan scaffolding pada level 2 dapat mengatasi kesalahan-kesalahan yang dilakukan kedua subjek.

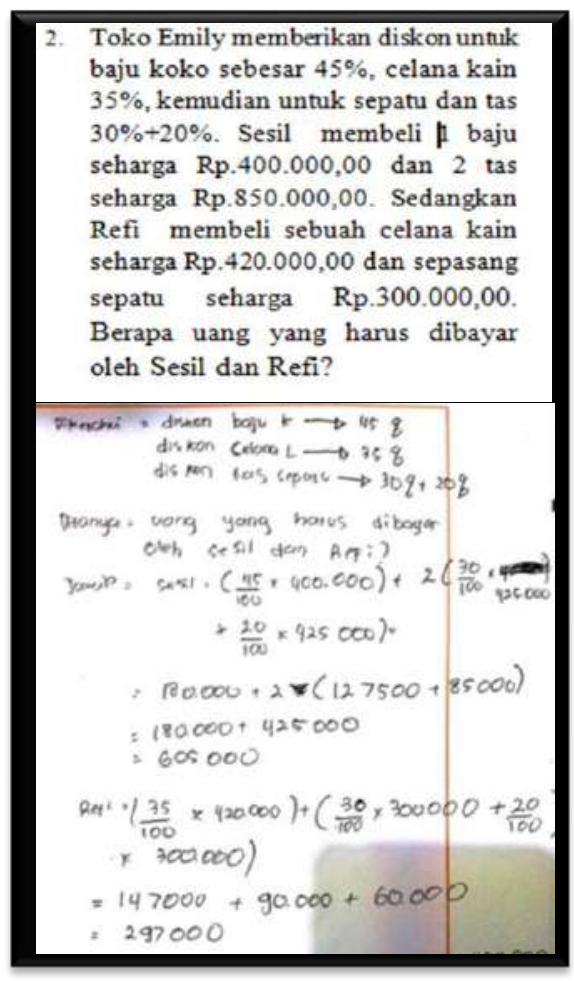

Gambar 13. Hasil Pekerjaan Subjek YR Pada Soal Tambahan Butir Soal Nomor 2.

Berdasarkan gambar 13, terlihat bahwa YR mengerjakan soal dengan benar dan penyelesaian dengan runtut, maka scaffolding dinyatakan selesai.

\section{Tipe 4, Weakness in Process Skill}

Kesalahan pada butir soal nomor 3 dilakukan oleh subjek DA, MI dan YR dengan kesalahan dalam melakukan perhitungan yang mengakibatkan kesalahan dalam hasilnya. Berikut pembahasan salah satu subjeknya.

\section{Sebelum Scaffolding}

Berdasarkan wawancara dengan subjek YR, diketahui jika subjek sudah tahu informasi yang terdapat pada soal, tetapi ia tidak dapat melanjutkan untuk menyelesaikan soal tersebut, karena 
bingung. Sehingga soal tidak terselesaikan dengan baik.

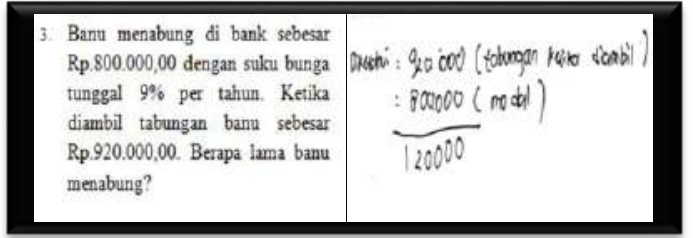

Gambar 14. Hasil Pekerjaan Subjek YR Pada Butir Soal Nomor 3.

\section{Bentuk Scaffolding}

Peneliti memberikan pertanyaan arahan agar subjek mengetahui informasi pada soal dan meminta subjek YR untuk memecahkan masalah. Scaffolding yang diberikan tersebut apabila dikategorikan dengan scaffolding Anghileri (2006), pemberian scaffolding ini berada pada level 2 explaining (menjelaskan), reviewing (meninjau), and restructuring (merestrukturasi).

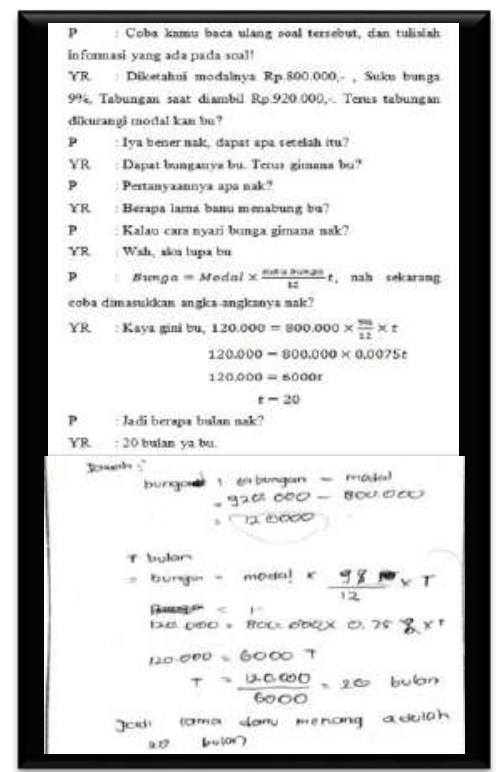

Gambar 15. Scaffolding Kesalahan Tipe 4 Pada Butir Soal Nomor 3.

\section{Setelah Scaffolding}

Setelah diberi scaffolding pada level 2 subjek mampu menyelesaikan materi aritmatika sosial, dan dapat dilihat pada gambar berikut ini.

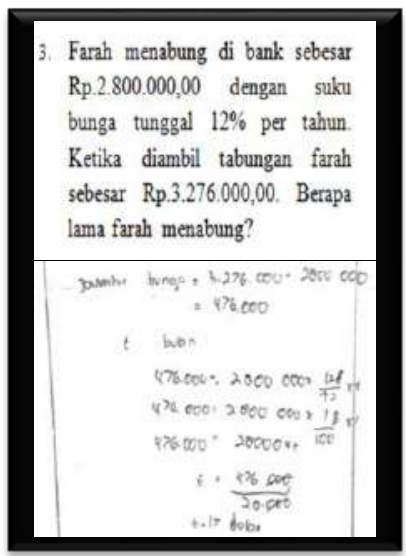

Gambar 16. Hasil Pekerjaan Subjek Pada Soal Tambahan Butir Soal Nomor 3.

Berdasarkan gambar 16, terlihat bahwa YR mengerjakan soal dengan benar dan penyelesaian dengan runtut, maka scaffolding dinyatakan selesai.

\section{E. Tipe 5, Encoding Error}

Kesalahan pada butir soal nomor 2 dilakukan oleh subjek DA, MI dan YR dengan kesalahan yang sama yaitu kurang teliti dalam membaca pertanyaan yang terdapat di dalam soal yang mengakibatkan kesalahan dalam menggunakan notasi. Berikut contoh hasil pekerjaan yang salah satu subjek.

\section{Sebelum Scaffolding}

Berdasarkan wawancara dengan subjek MI diketahui subjek tidak terlalu paham dengan soal sehingga tidak dapat menyelesaikan soal tersebut. Berikut ini hasil kesalahan subjek MI. 


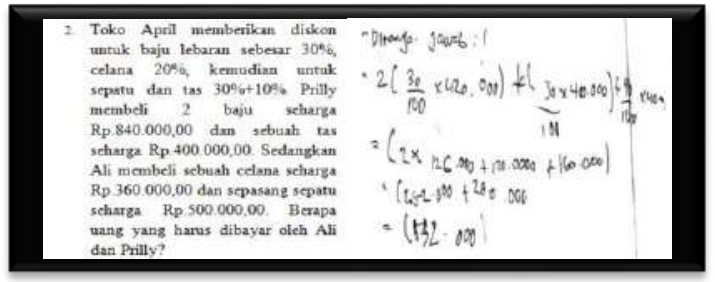

Gambar 17. Hasil Pekerjaan Subjek MI Pada Butir Soal Nomor 2.

\section{Bentuk Scaffolding}

Peneliti memberikan pertanyaan arahan agar subjek mengetahui informasi pada soal dan meminta subjek $\mathrm{Ml}$ untuk memecahkan masalah kemudian diminta melihat kembali hasil pekerjaanya. Scaffolding yang diberikan tersebut apabila dikategorikan dengan scaffolding Anghileri (2006), pemberian scaffolding ini berada pada level 2 explaining (menjelaskan).

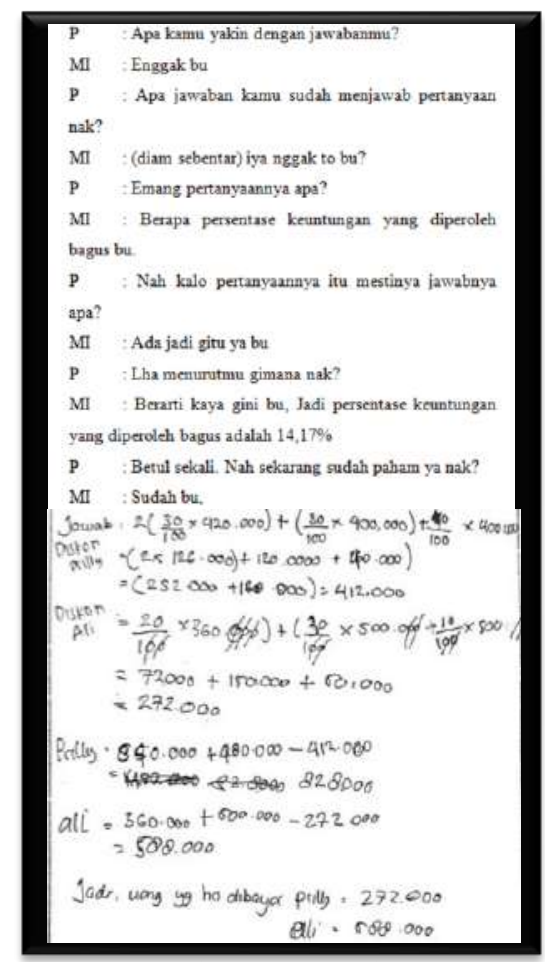

Gambar 18. Scaffolding Kesalahan Tipe 5 Pada Butir Soal Nomor 2.

\section{Setelah Scaffolding}

Setelah diberi scaffolding pada level 2 subjek mampu menyelesaikan materi aritmatika sosial, dan dapat dilihat pada gambar berikut ini.

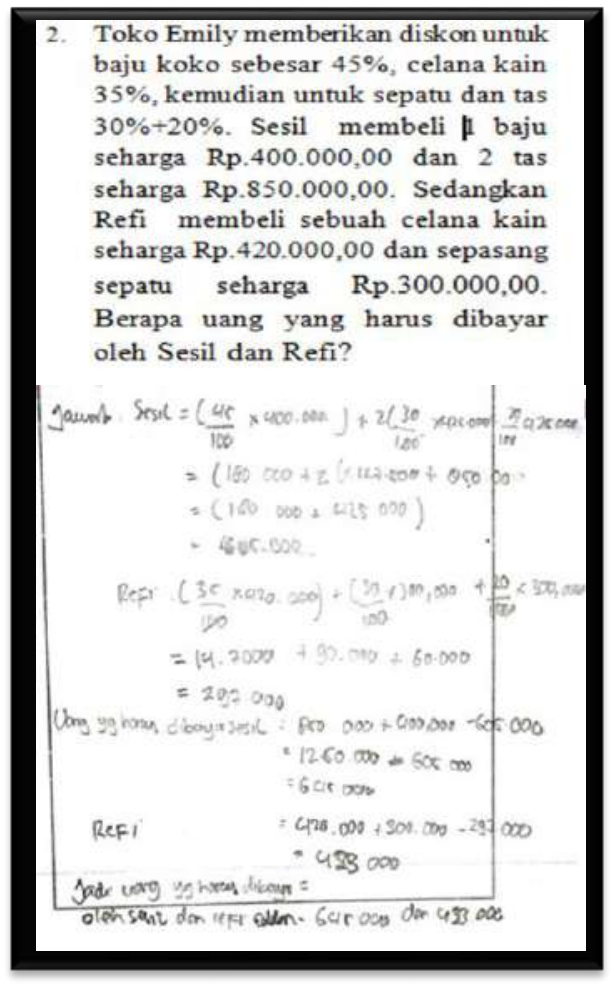

Gambar 19. Scaffolding Kesalahan Tipe 5 Pada Butir Soal Nomor 2.

Berdasarkan gambar 19, terlihat bahwa $\mathrm{Ml}$ mengerjakan soal dengan benar dan penyelesaian dengan runtut, maka scaffolding dinyatakan selesai.

\section{F. Temuan dalam Penelitian}

Selain pengelompokan kesalahan dan pemberian scaffolding pada masingmasing kesalahan. Terdapat temuan lain yang berkaitan dengan cara subjek dalam menyelesaikan soal cerita aritmatika sosial. 


\section{Tipe Kesalahan}

Kesalahan yang paling banyak dilakukan oleh subjek adalah kesalahan tipe 4 dan 5 yaitu, Weakness in Proses Skill dan Ecoding Error dengan persentase yang sama sebesar 31,82\%; Kesalahan yang lain memiliki persentase yang lebih rendah yaitu, Reading Error dengan persentase sebesar 8,33\%, Reading Comprehension Dificullty dengan persentase sebesar 13,64\%, dan Transform Error dengan persentase yang sama yaitu sebesar $14,39 \%$.

2. Soal Dengan Jumlah Salah Terbanyak.

Dari tiga soal cerita yang menjadi instrumen penelitian dengan indikator soal menyelesaikan soal cerita aritmatika sosial, terdapat banyak kesalahan terutama pada indikator menghitung jumlah biaya setelah diskon.

3. Subjek Dengan Pemberian Scaffolding Terbanyak

Terjadi pada butir soal nomer 2, untuk tipe kesalahan weakness in proses skill subjek $\mathrm{Ml}$ harus mengulang proses scaffolding hingga 3 kali baru dapat memahami dan menjawab soal dengan benar.

\section{Penutup}

Berdasarkan pembahasan diatas, dapat disimpulkan bahwa, Tipe kesalahan 1 reading error (kesalahan membaca) sebesar 8,33\%. Tipe kesalahan 2 reading comprehension difficulty (kesalahan memahami soal) sebesar 13,64\%. Tipe kesalahan 3 transform error (kesalahan tranformasi) sebesar 14,39\%. Tipe kesalahan 4 weakness in process skill (kesalahan keterampilan proses) sebesar 31,82\%. Kesalahan 5 encoding error (kesalahan menggunakan notasi) sebesar
$31,82 \%$. Kesalahan yang sering muncul adalah kesalahan tipe 4 dan 5 yaitu kesalahan dalam keterampilan proses dan kesalahan dalam menggunakan notasi. Pemberian scaffolding yang diberikan berdasarkan pada kesalahan yang dilakukan oleh subjek. Scaffolding yang diberikan pada kesalahan tipe I adalah explaining, scaffolding yang diberikan pada kesalahan tipe II adalah explaining, scaffolding yang diberikan pada kesalahan tipe III adalah explaining dan reviewing. Scaffolding yang diberikan pada kesalahan tipe IV adalah explaining, reviewing, dan restructuring, sedangkan scaffolding yang diberikan pada kesalahan tipe $\mathrm{V}$ adalah explaining.

Berdasarkan hasil penelitian diatas, peneliti dapat memberikan saran sebagai berikut: 1) Bagi guru, hendaknya dapat mengetahui kesalahan-kesalahan yang dilakukan oleh siswa dalam mengerjakan soal, dan dapat memberikan scaffolding kepada siswa yang mengalami kesulitan atau kesalahan dalam mempelajari materi matematika atau materi lain; dan 2) Bagi peneliti lain, dapat melakukan penelitian lanjutan mengenai pengembangan perangkat analisis kesalahan untuk materi aritmatika sosial ataupun pada materi yang lain, atau melakukan penelitian pengembangan pedoman scaffolding untuk materi aritmatika sosial ataupun pada materi yang lain.

\section{Daftar PUStaka}

Anghileri, J. (2006). Scaffolding Practices that Enhance Mathematies Learning. Journal of Mathematics Teacher Education.

Cahyani, R. (2015). Analisis Kesalahan Berdasarkan Teori Newman dan Pemberian Scaffolding dalam 
Menyelesaikan Soal Penjumlahan dan Pengurangan Bentuk Aljabar Siswa Kelas VIII A SMP Negeri 7 Salatiga.

Clement, M. N. (1980). (Analysing Children's Error on Mathematical Task. Educational Studies in Mathematika.

Felayani, M. R. (2013). Pembentukan Karakter dan Pemecahan Masalah Melalui Model Probing Prompting Berbantuan Scaffolding Materi Barisan dan Deret Kelas XI SMK.

Grahita, A. (2014). Identifikasi Kesalahan

Siswa dan Pemberian Scaffolding dalam Menyelesaikan Soal Matematika pada Materi Operasi Pecahan Bentuk Aljabar Kelas VII C SMP Pangudi Luhur Salatiga .

Nursalim, D. (2011). Psikologi Pendidikan. Surabaya: Unesa University Press.

Putri, J. D. (2016). Analisis Kesalahan Menurut Newman dan Pemberian Scaffolding pada Materi Luas Segitiga dengan Aturan Sinus dan Cosinus Bagi Siswa XI MIA 1 SMA Kristen Satya Wacana Salatiga.

Rahayu, I. A. (2015). Analisis Kesalahan Menurut Teori Newman dan Pemberian Scaffolding pada Soal Cerita Segitiga dan Segiempat Bagi Siswa Kelas VII SMP Kristen Bendungan Kabupaten Wonosobo.

Setyono, D. (2013). Kesalahan Menyelesaikan Soal Matematika dalam Bentuk Soal Cerita Pokok Bahasan Aritmatika Sosial.
Sugiyono. (2010). Metode Penelitian Pendidikan (pendidikan kuantitatif, kualitatif, dan R\&D). Bandung: Alfabeta.

Sugiyono. (2013). Metode Kualitatif Kuantitatif dan R\&D. Bandung: Alfabeta.

Widiasa, K. P. (2012). Analisis Tipe Kesalahan Siswa dan Pemberian Scaffolding dalam Menyelesaikan Soal Materi Operasi Bilangan Pecahan Kelas VII C SMP Kristen Satya Wacana Salatiga.

\section{Riwayat Hidup Penulis}

Puji Lestari Susilowati, S.Pd.
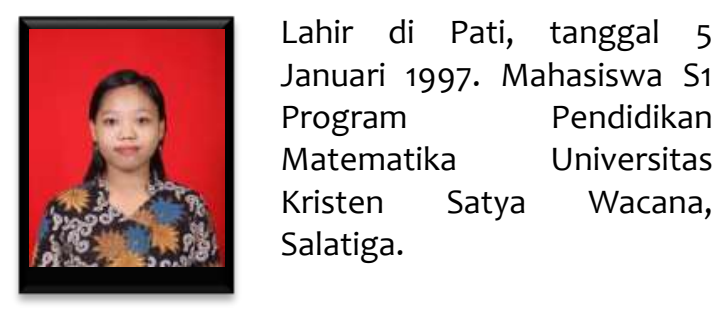
Januari 1997. Mahasiswa S1 Program Pendidikan Matematika Universitas Kristen Satya Wacana, Salatiga.

\section{Novisita Ratu, S.Pd. M.Pd.}

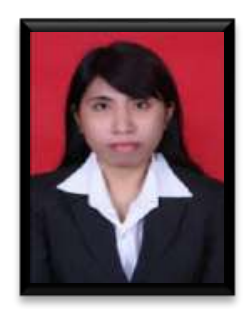

Lahir di Kupang, tanggal 07 November 1981. Dosen Program Pendidikan Matematika Universitas Kristen Satya Wacana, Salatiga. S1 Matematika Universitas Sanata Dharma Yogyakarta, S2 Manajemen Pendidikan Universitas Kristen Satya Wacana Salatiga. Presenter di AMD (Asian Mathematics Conference), dan mendapat Short Course dari Australia Award Fellowship di Sun Shine Coast University Australia. 